\title{
Manifestation of eosinophilic granulomatosis with polyangiitis in head and neck*
}

\author{
Hannes Petersen ${ }^{1 \#}$, Paul Götz" ${ }^{1 \#}$, Marcus Both², Matthias Hey' , Petra \\ Ambrosch', Jan Phillip Bremer ${ }^{3}$, Julia Holle ${ }^{3}$, Frank Moosig ${ }^{3}$, Martin Laudien' \\ ' Department of Otorhinolaryngology, Head and Neck Surgery, University of Kiel, Kiel, Germany \\ 2 Department of Radiology and Neuroradiology, University Hospital Schleswig-Holstein, Campus Kiel, Kiel, Germany \\ ${ }^{3}$ Klinikum Bad Bramstedt, Department of Rheumatology and University Hospital Schleswig-Holstein, Bad Bramstedt, Germany
}

Rhinology 53: 277-285, 2015

DOl:10.4193/Rhino14.074

*Received for publication:

March 16, 2014

Accepted: March 5, 2015

\# Both authors have equally contributed to this article

\begin{abstract}
Introduction: Besides an obvious clinical involvement of the ear, nose and throat (ENT)-region in Eosinophilic Granulomatosis with Polyangiitis (EGPA), systematic data is sparse. Only a few case series and case reports are available that particularly describe rhinological, otological or other manifestations of EGPA in the ENT-region. Therefore, the objective of this study is to systematically describe data on ENT-region involvement in a large series of EGPA patients.
\end{abstract}

Method: EGPA patients examined in the Department of Otorhinolaryngology of the Christian-Albrechts-University of Kiel between 1990 and 2010 were included in the study. Criteria for ENT-manifestation were assigned to five subgroups (history, ENT examination, audiological and rhinological diagnostic findings and cranial MRI) and documented cumulatively. EGPA patients were examined in a standardized way based on the validated Ear Nose and Throat Activity Score (ENTAS) or its precursor, including audiological and rhinological diagnostic findings. MRI scans were analysed to further evaluate ENT involvement.

Results: A total of 95 EGPA patients were included in the study. In approximately $80 \%$ of them, ENT-involvement was documented and the assumption of a frequent rhinological manifestation in patients with EGPA was confirmed. Moreover, the data reveals remarkable evidence for an otological manifestation. A missing correlation between the rhinological and the otological manifestation indicates an independent autoimmune-inflammatory process for this manifestation.

Conclusion: The data of the largest monocentric study presented here confirms the hypothesis of a frequent ENT involvement in EGPA patients, in whom rhinological and otological manifestations are most common. Therefore, treatment should include long term follow-up and should be managed interdisciplinary.

Key words: EGPA, ENT, eosinophilic granulomatosis with polyangiitis, Churg-Strauss syndrome, head and neck

\section{Introduction}

The Antineutrophil Cytoplasmatic Antibody (ANCA)-associated small-vessel vasculitis Eosinophilic Granulomatosis with Polyangiitis (EGPA, Churg-Strauss syndrome) is a rare autoimmune disease of unknown aetiology. EGPA was first described as "allergic angiitis and allergic granulomatosis" in 1951 by Churg and Strauss ${ }^{(1,2)}$. Besides the appearance of blood and tissue eosinophilia, eosinophil-rich broncho-alveolar infiltrates and asthma, the head and neck region seems to be involved regularly (3-14). In 1984, Lanham et al. described 3 phases. The 1st phase (pro- dromal phase) is characterized by asthma, frequently allergic rhinitis and recurring rhinosinusitis with nasal polyps. This phase may persist for many years. In the 2 nd phase, peripheral blood eosinophilia and eosinophilic tissue infiltrates occur and may persist for years, until finally the life-threatening 3rd phase (vasculitic phase) affecting extrapulmonary organs is reached ${ }^{(8,15)}$.

The occurrence of vasculitic manifestations in a patient with known allergic rhinitis, chronic rhinosinusitis with polyps and late-onset asthma is pathognomonic (2). 
Besides the above mentioned clinical obvious involvement of the ear, nose and throat (ENT)-region, EGPA scoring systems relying on expert consensus emphasizing such involvement. Surprisingly only a few case series and case reports are available, that particularly describe rhinological, otological or other manifestations ${ }^{(6,15-23)}$.

Therefore, the objective of this study is to describe the ENTregion involvement in EGPA.

\section{Patients and methods}

Study design and population

EGPA patients seen in the Department of Otorhinolaryngology of the Christian-Albrechts-University of Kiel between 1990 and 2010 were included in the study. The ENT examination is a fundamental part of the clinical work within the interdisciplinary vasculitis referral center as described elsewhere ${ }^{(24)}$.

Vasculitis was diagnosed histologically or by clinical surrogate parameters. In addition 4 of the 6 ACR-classification criteria had to be fulfilled ${ }^{(25)}$.

\section{Development of the data collection table}

Criteria for ENT-manifestation were primarily defined using the ENT Activity Score (ENTAS), a validated ENT examination method for vasculitis, results of literature research and criteria of established indices as well as definitions ${ }^{(26)}$. Finally, ENT-manifestations becoming apparent during chart examination were included. The criteria were assigned to five subgroups (history, ENT examination, audiological diagnostic, rhinological diagnostic and radiology).

\section{Data collection}

EGPA-patients were examined in a standardized process based on the validated ENTAS or its precursor ${ }^{(26)}$. In addition, the available MRI data (indication: suspected CNS-involvement) was analysed with respect to the sinuses and the temporal bone. Frequent conspicuous data were further analysed.

\section{Audiology}

The WHO hearing level was determined for the better hearing ear ${ }^{(27,28)}$. Additionally, the audiological data was compared to the age and sex-specific standardized data of the DIN EN ISO 7029:2000 for otologically normal people ${ }^{(29)}$.

To avoid an overrepresentation of patients with more than one measurement, the average of the air conduction data from both ears was determined. To analyse the influence of a possible conductive hearing loss, the difference between air and bone conduction was calculated and tympanograms were analysed. In each MRI, opacification in the middle ear and mastoid on both sides were evaluated by an experienced investigator (MB).

\section{Rhinology}

The olfactory function was tested by the "Sniffin'Sticks Screening $12^{\prime \prime}$ test ${ }^{(30)}$. The objective ability to breathe through the nose was evaluated by active anterior rhinomanometry before and after decongestion. A flow of $<300 \mathrm{ml} / \mathrm{s}\left(\mathrm{cm}^{3} / \mathrm{s}\right)$ at $150 \mathrm{~Pa}$ was defined as a severe obstruction and a flow $\geq 300$ $\mathrm{ml} / \mathrm{s}\left(\mathrm{cm}^{3} / \mathrm{s}\right)$ at 150 Pa was classified as a mild or no obstruction [device specific standard values and validated grading ${ }^{(31)}$ ]. Since patients had multiple measurements with fluctuating results, patients were subdivided into different levels of obstruction (Level A: patients with exclusively $<300 \mathrm{ml} / \mathrm{s}$ results, Level C: patients with thresholds $\geq 300 \mathrm{ml} / \mathrm{s}$ results and Level $B$ for those patients with variable results).

A modified (omitting the ostiomeatal complex because of low reproducibility in MRI) Lund-Mackay-score was used for the evaluation of MRI scans of the sinuses ${ }^{(32-37)}$.

In addition, the existence or absence of a fluid level in the maxillary sinus was evaluated and the thickness of the mucosa of all sinuses was measured to distinguish acute and chronic inflammation ${ }^{(38,39)}$.

\section{Statistical analysis}

Statistical analysis was performed using SPSS (Statistical Package for the Social Sciences, Version 20) and MS Excel (Microsoft Office XP, Version $2003+2007$ )

The existence of any association between signs of an inflammatory process [defined as rhinosinusitis according to the clinical definition of rhinosinusitis by the European Position Paper on Rhinosinusitis and Nasal Polyps $2012^{(40)}$ of the nasal mucosa and a hearing loss based on the WHO classification (hypothesis I) was analysed. Furthermore, an opacification in the MRI of the mastoid and/ or the middle ear (hypothesis II) was analysed with respect to said inflammatory process of the nasal mucosa. To avoid the influence of multiple examinations, only data of the first examination was used.

\section{Results}

\section{Patient characteristics}

In this study, 95 patients were included (46 women [48\%] and 49 men [52\%]). There were a total of 295 consultations with each patient having anywhere from 1 to 26 consultations. The average age at diagnosis was 51 years (range: 16-75) and the age at first manifestation was on average 46 years (range: 15-72).

The average Birmingham Vasculitis Activity Score (BVASV3) was 5 (range: 0 - 25; SD = 5.95). The average Vasculitis Damage Index (VDI) was 2 (range: $0-11 ; \mathrm{SD}=2.36$ ).

In $33 \%(n=31)$ of the patients, ANCA were detected $(4 \%, n=4$, C-ANCA and 28\%, $n=27$ P-ANCA) with $1 \%(n=1)$ anti-PR3 and 

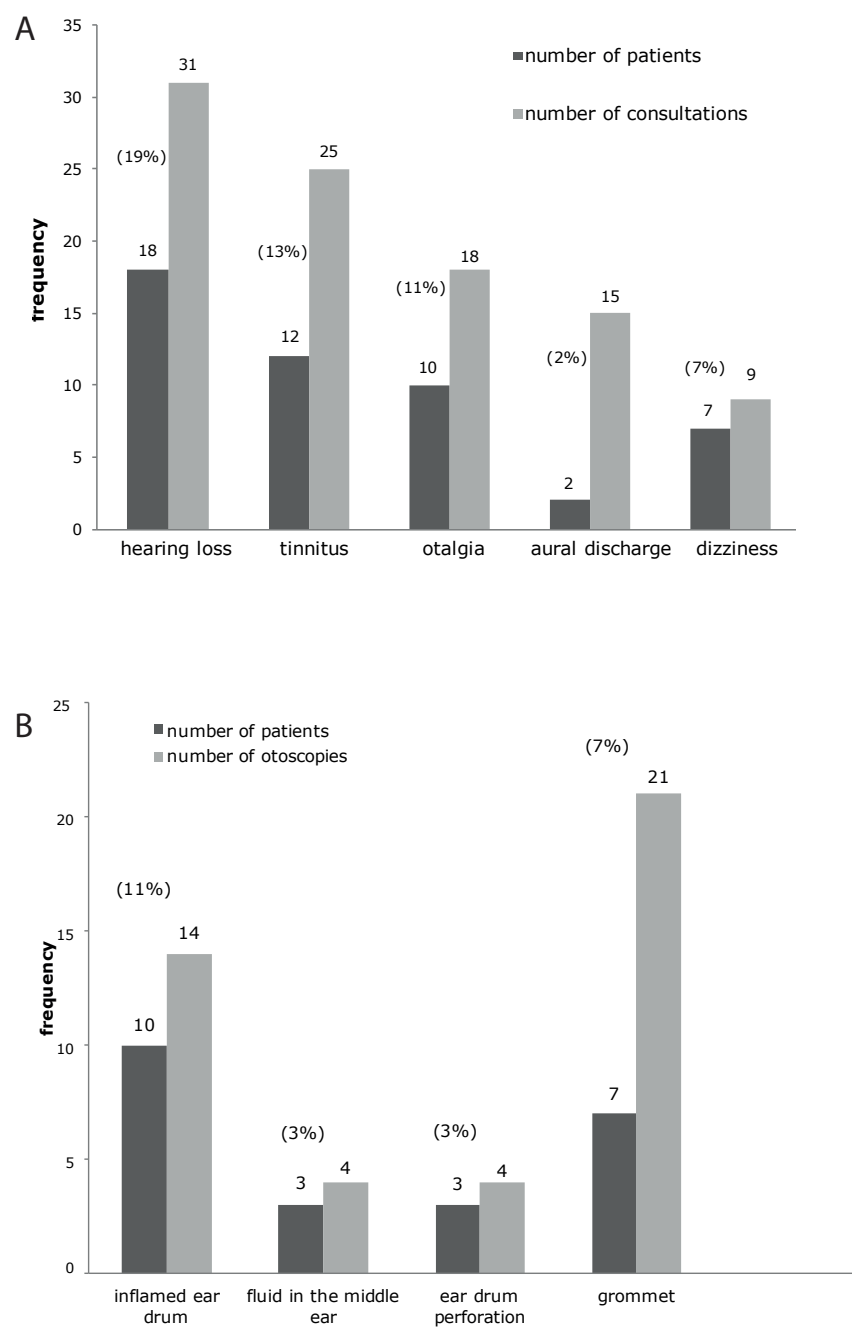

Figure 1. A) Positive history for hearing loss, tinnitus, otalgia, aural discharge and dizziness (95 patients with 295 consultations). B) Positive findings for inflamed ear drum, fluid in the middle ear, ear drum perforation and grommet (95 patients with 295 otoscopies).

$25 \%(n=24)$ anti-MPO specificity. The average prednisolone dosage was $11 \mathrm{mg}$ (range 0 - 29, SD $5.57 \mathrm{mg}$ ). Further, patients received a variance of different immune modulatory medication (cyclophosphamide, methotrexate, azathioprine, interferon, leflunomide, mycophenolatmofetil, mycophenolatnatrium, cyclosporin A, rituximab, infliximab, etanercept, adalimumab).

\section{Otological manifestation}

\section{Medical history}

Patients reported subjective hearing loss in 19\% $(n=18)$. Thirteen percent of the patients $(n=12)$ complained about tinnitus and $11 \%$ about otalgia $(n=10)$. Two percent of the patients $(n=2)$ suffered from aural discharge and $7 \%(n=7)$ from dizziness (Figure 1a).
Table 1. Level of hearing loss based on the WHO classification for the better hearing ear (209 pure tone audiometries of 89 patients; multiple entries).

\begin{tabular}{|c|c|c|c|c|}
\hline $\begin{array}{l}\text { Level of } \\
\text { hearing loss }\end{array}$ & ISO-data & $\begin{array}{l}\text { number } \\
\text { of } \\
\text { patients }\end{array}$ & $\begin{array}{c}\text { number of } \\
\text { measure- } \\
\text { ments }\end{array}$ & \\
\hline Level 0 & $(\leq 25 \mathrm{~dB})$ & 80 & 173 & \\
\hline Level 1 & $(26-40 \mathrm{~dB})$ & 15 & 27 & \multirow{4}{*}{$\begin{array}{c}\text { equates } \\
19 \text { patients } \\
=> \\
21 \% \text { of } \\
n=89\end{array}$} \\
\hline Level 2 & $(41-60 d B)$ & 5 & 5 & \\
\hline Level 3 & $(61-80 \mathrm{~dB})$ & 1 & 4 & \\
\hline Level 4 & $(\geq 81 \mathrm{~dB})$ & 0 & 0 & \\
\hline
\end{tabular}

\section{Otoscopy}

An inflamed eardrum was documented in $11 \%$ of the patients $(n=10)$. In $3 \%$ of the patients $(n=3)$, fluid in the middle ear and ear drum perforation was detected. Additionally in $7 \%$ of the patients $(n=7)$, grommets could be identified (Figure1b). Audiology

For the evaluation of hearing ability, pure tone audiograms were conducted for 89 patients, 209 for the right ear (1 - 9 audiogramms per patient) and 218 for the left ear (1 - 12 audiogramms per patient). For each pure tone audiogram available for both sides, the level of hearing loss was evaluated based on the WHO classification ${ }^{(27,28)}$ (Table 1 ).

Hearing loss was diagnosed in $21 \%$ of the patients ( $n=19$ of 89 , multiple entry due to multiple examinations: slight impairment in $17 \%$ of the patients [ $n=15$ of 89 ], moderate impairment in $6 \%$ [ $n=5$ of 89 ] and severe impairment in $1 \%$ of the patients [ $n$ $=1$ of 89$]$ ).

Furthermore, data of sound conduction of both ears between 0.125 - $8 \mathrm{kHz}$ was compared to data of DIN EN ISO 7029:2000 (29) (Figure 2). On the left side, a divergence from the norm with a minimum of $7 \mathrm{~dB}$ at $1 \mathrm{kHz}$ and a maximum of $11 \mathrm{~dB}$ at $6 \mathrm{kHz}$ was detected. Similarly on the right side, a minimum of $8 \mathrm{~dB}$ at $3 \mathrm{kHz}$ and a maximum of $13 \mathrm{~dB}$ at $6 \mathrm{kHz}$ was assessed.

Figure 3 shows the difference between sound and bone conduction for both ears between $0.25-6 \mathrm{kHz}$. On the left ear, there is a minimum difference of $5 \mathrm{~dB}$ at $2 \mathrm{kHz}$ and a maximum of $10 \mathrm{~dB}$ at $6 \mathrm{kHz}$. Similarly, a minimum difference of $5 \mathrm{~dB}$ at $2 \mathrm{kHz}$ and a maximum difference of $10 \mathrm{~dB}$ at $0.25 \mathrm{kHz}$ were detected on the right side.

Corresponding tympanograms of 86 patients (205 right and 203 left side [range right: 1-9 tympanograms per patient; left: 1-10 tympanograms per patient]) were analysed. The median 


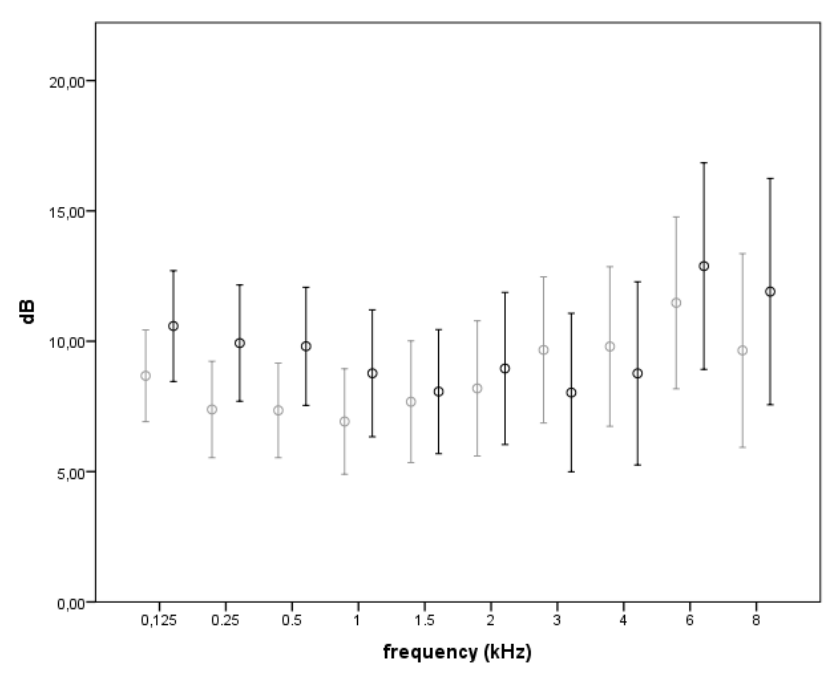

Figure 2. Average and $95 \%$ confidence interval of the divergence of the hearing threshold level from the age and sex-specific norm data (DIN EN ISO 7029:2000) for both ears between 0.125-8 kHz. (grey: left ear, 218 audiograms; black: right ear, 209 audiograms).

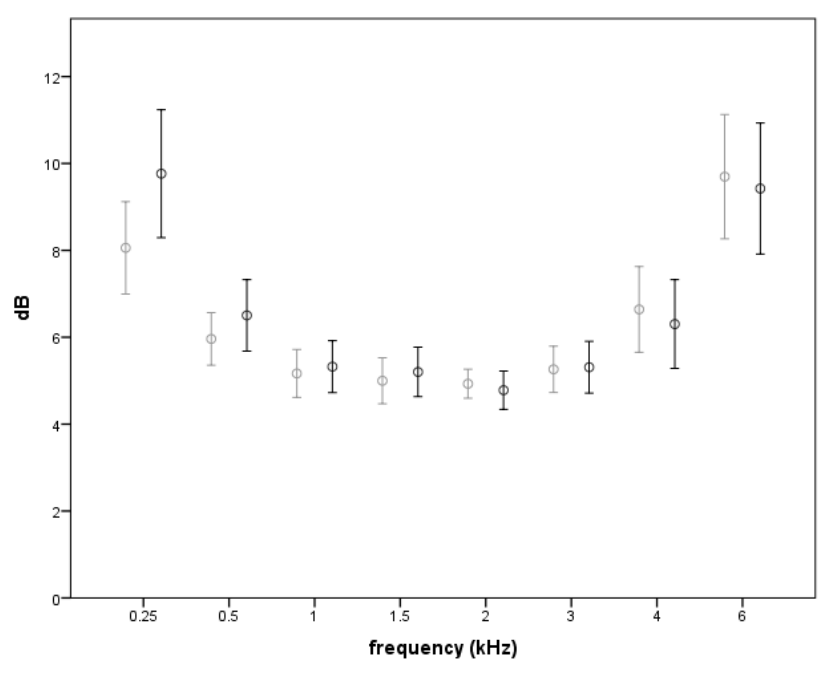

Figure 3. Average and $95 \%$ confidence interval of the difference between the sound conduction and the bone conduction for both ears between $0.25-6 \mathrm{kHz}$ ( $\mathrm{n}=89$ ) (grey: left ear, 218 audiograms; black: right ear, 209 audiograms). compliance on the right side was $0.8 \mathrm{ml}$ (average: $1.0 \mathrm{ml}$; upper quartile: $1.2 \mathrm{ml}$; lower quartile: $0.5 \mathrm{ml}$ ) and on the left side $0.8 \mathrm{ml}$ (average: $1.0 \mathrm{ml}$; upper quartile: $1.4 \mathrm{ml}$; lower quartile: $0.6 \mathrm{ml}$ ). A median of $10 \mathrm{daPa}$ (average: $22 \mathrm{daPa}$; upper quartile: $22 \mathrm{daPa}$; lower quartile: $5 \mathrm{daPa}$ ) on the right and $11 \mathrm{daPa}$ (average: 28 daPa; upper quartile: 26 daPa; lower quartile: $5 \mathrm{daPa}$ ) on the left ear was documented for middle ear pressure.

\section{Radiological results of the temporal bone}

Thirty nine patients had 56 MRI's of the head including the temporal bone. An opacification in the middle ear was detected in $13 \%$ of the patients $(n=5)$. The assessment of the mastoid has shown an opacification in $49 \%$ of the patients $(n=19$, Table 2 ).

Rhinological manifestation

Table 2. Level of opacification of the middle ear and mastoid in the MRI of the temporal bone of both sides.

\begin{tabular}{|c|c|c|c|c|}
\hline & & no opacification & \multicolumn{2}{|c|}{ opacification } \\
\hline & Number of MRIs & 47 & \multicolumn{2}{|c|}{9} \\
\hline Right middle ear & number of patients (multiple entries) & 35 & \multicolumn{2}{|c|}{5} \\
\hline & total number of patients with a shadow & & \multicolumn{2}{|c|}{5 (13\% of $n=39$ patients) } \\
\hline \multirow{4}{*}{ Left middle ear } & Number of MRIs & 51 & \multicolumn{2}{|c|}{5} \\
\hline & number of patients (multiple entries) & 37 & \multicolumn{2}{|c|}{2} \\
\hline & total number of patients with a shadow & & \multicolumn{2}{|c|}{$2(5 \%$ of $n=39$ patients) } \\
\hline & & no opacification & partial opacification & total opacification \\
\hline \multirow{3}{*}{ Right mastoid } & number of MRIs & 32 & 19 & 5 \\
\hline & number of patients (multiple entries) & 23 & 15 & 5 \\
\hline & total number of patients with a shadow & & \multicolumn{2}{|c|}{18 (46\% of $n=39$ patients) } \\
\hline \multirow{3}{*}{ Left mastoid } & number of MRIs & 39 & 11 & 6 \\
\hline & number of patients (multiple entries) & 30 & 10 & 3 \\
\hline & total number of patients with a shadow & & \multicolumn{2}{|c|}{13 (33\% of $n=39$ patients) } \\
\hline
\end{tabular}



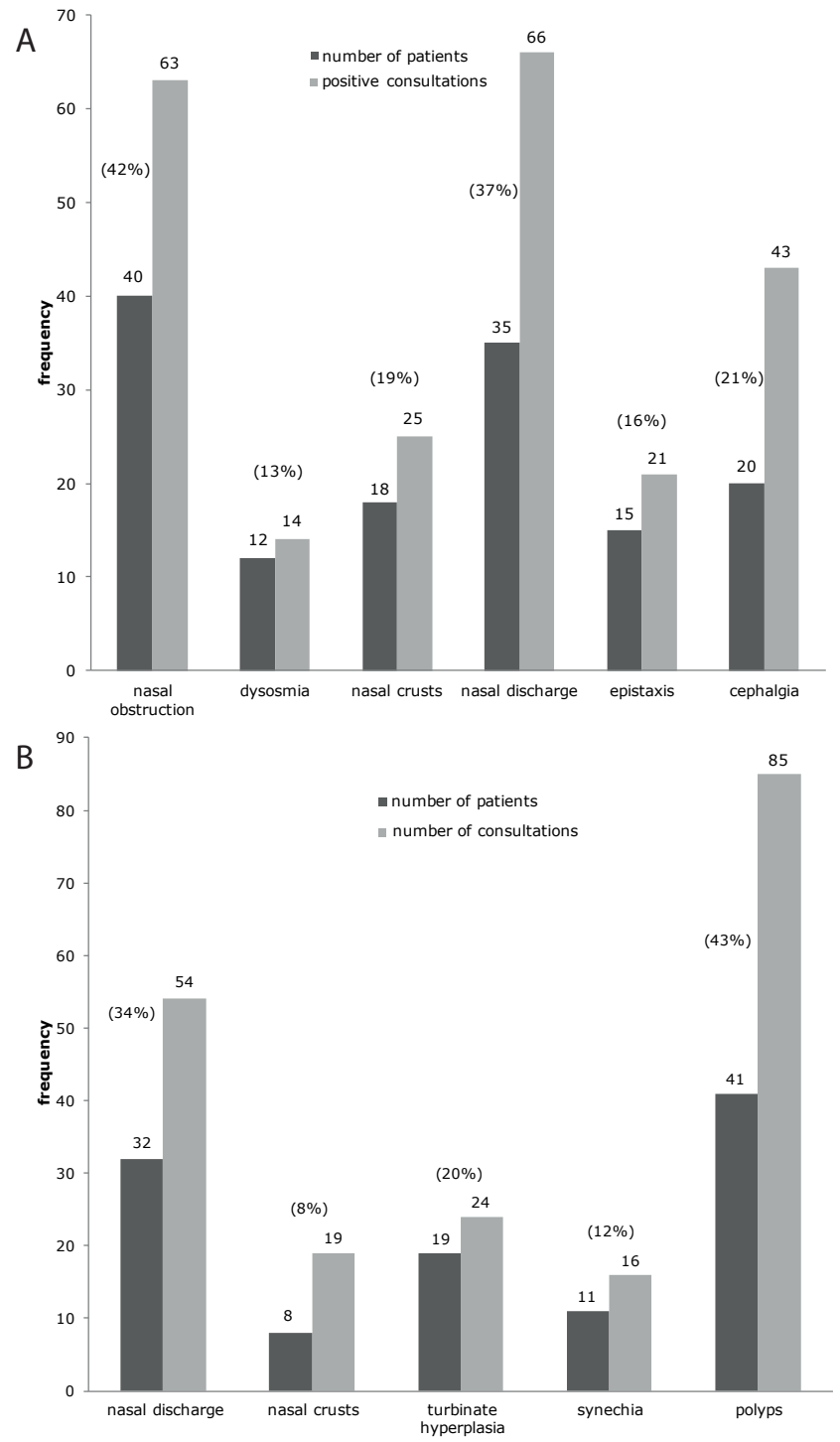

Figure 4. A) Positive history for nasal obstruction, dysosmia, nasal discharge, epistaxis and cephalgia (95 patients with 295 consultations). B) Positive findings for nasal discharge, nasal crusts, turbinate hyperplasia, synechia and polyps (95 patients with 295 rhinoscopies).

\section{Medical history}

Forty two percent of the patients $(n=40)$ complained about nasal obstruction. A dysosmia was reported in $13 \%$ of the patients $(n=12)$. Nasal crusts were complained about by $19 \%$ of the patients $(n=18)$ and nasal discharge by $37 \%$ of the patients ( $n$ $=35)$. Epistaxis was reported by $16 \%$ of the patients $(n=15)$ and $21 \%(n=20)$ complained about cephalgia (Figure $4 a)$. Both history and rhinoscopic information suggested past surgery of the nose in $43 \%$ of the patients $(n=41)$. Thirty seven percent of the patients $(n=35)$ had sinus surgeries, $8 \%(n=8)$ had polypectomies and a septumplasty was done in $6 \%$ of the patients $(n=6)$.

Rhinoscopy

The appearance of nasal discharge was documented in 34\%

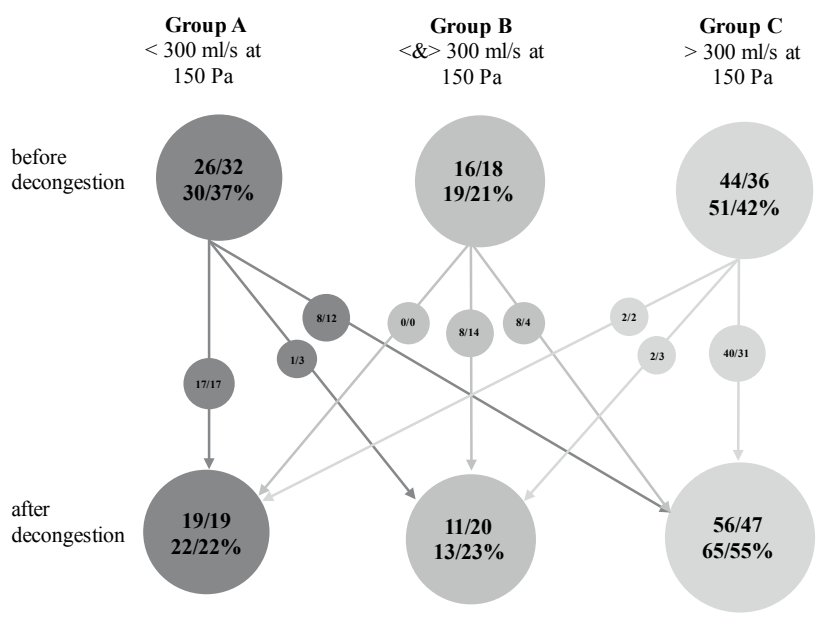

Figure 5. Level of nasal obstruction in the rhinomanometry of the right/ left side before and after decongestion by Xylometazolin $0.1 \%$ (86 patients with 178 rhinomanometries).

of the patients $(n=32)$. Nasal crusts were seen in $8 \%$ of the patients ( $n=8)$, a hyperplasia of the turbinates in $20 \%$ of the patients $(n=19)$ and synechia in $12 \%$ of the patients $(n=11)$. Polyps could be demonstrated in $43 \%$ of the patients ( $n=$ 41 , Figure $4 b)$. Forty percent of the patients $(n=38)$ showed changes of the nasal mucosa like swelling/edema, irritation and vulnerability. A swollen, edematous mucosa was seen in $12 \%$ of the patients $(n=11)$.

\section{Olfactory test}

The olfactory system was analysed using the results of 118 Sniffin' sticks-tests ( 1 - 5 tests per patient) of $65 \%$ of the patients ( $n=62$ of 95$)$. In $79 \%$ of the patients $(n=49)$ a normosmia, in $11 \%$ of the patients $(n=7)$ a hyposmia and in $29 \%$ of the patients $(n=18)$ anosmia was observed. Dysosmia was observed in $40 \%$ of the tested patients $(n=25)$.

\section{Rhinomanometry}

One hundred seventy eight rhinomanometries of 86 patients were evaluated. A severe obstruction (group A) before decongestion was detected in about $30 \%$ of the patients (right side $30 \%, \mathrm{n}=26$ and left side $37 \%, \mathrm{n}=32$ ). On the other hand, approximately $50 \%$ of the patients (right side $51 \%, n=44$ and left side $42 \%, n=36$ ) had little to no obstruction (group C). In about $20 \%$ of the patients (right side $19 \%, n=16$ and left side $21 \%, n=$ 18), varying results were observed over time (group B). After decongestion of the nasal mucosa, in more than $50 \%$ of the patients of group A (right side $65 \%, n=17$ of 26 and left side $53 \%, n=17$ of 32 ) still a severe obstruction was detected. However, almost all patients of group C (right side $91 \%, n=40$ of 44 and left side $86 \%, n=31$ of 36 ) stayed above $300 \mathrm{ml} / \mathrm{s}$. Twenty to $50 \%$ of the patients of group B switched to group C 
Table 3. Level of mucosa thickness of the sinuses.

\begin{tabular}{|lccc} 
Sinus & $\begin{array}{c}\text { no mucosa } \\
\text { swelling }\end{array}$ & $\leq 3 \mathrm{~mm}$ & $>\mathbf{3} \mathrm{mm}$ \\
\hline maxillaris right & $7(12.5 \%)$ & $18(32.1 \%)$ & $31(55.4 \%)$ \\
\hline maxillaris left & $10(17.9 \%)$ & $18(32.1 \%)$ & $28(50 \%)$ \\
\hline ant. ethmoidalis right & $1(1.8 \%)$ & $25(44.6 \%)$ & $30(53.6 \%)$ \\
\hline ant. ethmoidalis left & $3(5.4 \%)$ & $24(42.9 \%)$ & $29(51.8 \%)$ \\
\hline post. ethmoidalis right & $12(21.4 \%)$ & $28(50 \%)$ & $16(28.6 \%)$ \\
\hline post. ethmoidalis left & $13(23.2 \%)$ & $22(39.3 \%)$ & $21(37.5 \%)$ \\
\hline sphenoidalis right & $22(39.3 \%)$ & $24(42.9 \%)$ & $10(17.9 \%)$ \\
\hline sphenoidalis left & $19(33.9 \%)$ & $22(39.3 \%)$ & $15(26.8 \%)$ \\
\hline frontalis right & $22(39.3 \%)$ & $26(46.4 \%)$ & $8(14.3 \%)$ \\
\hline frontalis left & $25(44.6 \%)$ & $22(39.3 \%)$ & $9(16.1 \%)$ \\
\hline
\end{tabular}

(right side $50 \%, \mathrm{n}=8$ of 16 and left side $22 \%, \mathrm{n}=4$ of 18 ) the other showed no shift after decongestion (right side $50 \%, \mathrm{n}=8$ of 16 and left side $78 \%, n=14$ of 18 , Figure 5 ).

Analyzing both sides together, $15 \%$ of the patients $(n=13)$ showed a severely obstructed nose (group $A$ ) in all measurements. After decongestion, $8 \%$ of the patients $(n=7)$ kept a severe both-sided nasal obstruction. However, $31 \%$ of the patients ( $n=$ 27) showed data above $300 \mathrm{ml} / \mathrm{s}$ on both sides before decongestion. After decongestion the remaining patients made up $27 \%(n=23)$.

\section{Radiological results of the sinuses}

In total, 56 MRIs of the sinuses of 39 patients (range: 1 - 4) were evaluated. Excluding the ostiomeatal complex, the average of the Lund-Mackay-score was 8.84 (range: 1 - 16, SD: 3.460).

In the MRIs of two patients $(4 \%, n=2)$, air fluid levels were documented in the maxillary sinuses. A thickened mucosa of $>3$ $\mathrm{mm}$ was detected in the maxillary and anterior ethmoid sinuses in $\geq 50 \%$ of MRIs. Moreover, thickened mucosa of $>3 \mathrm{~mm}$ was also detected in about $15 \%$ in the frontal sinuses, in $33 \%$ in the posterior ethmoid sinuses and in $20 \%$ in the sphenoid sinuses (Table 3).

\section{Statistical analysis of hypotheses I and II}

The statistical analysis by the chi-square-test demonstrated no association between the attributes of an inflamed nasal mucosa and the existence or the absence of a hearing loss according to the WHO classification (hypothesis I). Additionally, it can be con- cluded that there is no association between an inflamed nasal mucosa and an opacification in the MRI of the mastoid and/ or middle ear (hypothesis II).

\section{Discussion}

Together with Granulomatosis with Polyangiitis (GPA, Wegener's) and microscopic polyangiitis (MPA), EGPA belongs to the ANCA-associated small-vessel-vasculitides.

Eosinophils are considered as key mediators. They damage tissue by releasing their toxic granule constituents and are involved in the modulation of the immune response. While the pathogenetic role of anti-neutrophil cytoplasmic antibodies (ANCA) is still uncertain, B-cells seem to activate T-cells, which secrete IL5, the main survival factor for eosinophils $(3,14,41)$.

The gender distribution with a ratio of 1:1 and the mean age of 51 years at diagnosis confirm the data of previous studies ${ }^{(3,16)}$. With the mean BVASV3 of 5 a low activity of vasculitis was documented in the cohort. This is similar to a low damage documented by the mean VDI of 2 .

As a major symptom, a subjective hearing loss was detected in $19 \%$ of the patients and corresponding results could be demonstrated by audiograms ${ }^{(27-29)}$.

Compared to epidemiological data, based on WHO classification, the results presented are above the reported prevalence of hearing loss ${ }^{(42)}$.

A few case reports have indicated an otological manifestation of EGPA [uni- or bilateral conductive hearing loss, a sensorineural hearing loss or a combination of both ${ }^{(15,17-19,21,22)}$ ].

Regarding a conductive hearing loss, both the results of the pure tone audiogram and the results of the tympanograms do not indicate a higher conductive component. Furthermore, there was no statistical association between an inflamed nasal mucosa and a hearing loss with respect to a secondarily induced serous otitis media (hypothesis I) as described for GPA ${ }^{(43,44)}$. The occurrence of tinnitus and dizziness in about $10 \%$ of patients support the hypothesis of a mostly sensorineural damage. The cause of an involvement of the inner ear/central nervous system as a complication of a vasculitis is yet to be sufficiently investigated ${ }^{(43)}$. However, 6-10\% of EGPA patients show a CNS involvement, in which palsies of central nerves are described $(3,5,8,45-48)$. In addition to a secondary labyrinthitis, a vasculitis of the Aa. labyrinthi or its branches including necrotizing granuloma could also lead to neuronal or local damages causing a sensorineural hearing loss ${ }^{(18)}$.

Ishiyama and Canalis as well as Bacciu et al. described an improvement of the otological symptoms after immunosuppressive therapy supporting the hypothesis of a damage by vasculitis $(15,18)$.

Furthermore, the history and the otoscopic data suggest an inflammation of the middle ear for a small percentage of patients. In relation to this, an increased opacity of the mastoid was pro- 
minently observed. MRI-studies show one or dual-sided opacity of the mastoid in $19-27 \%$ in otologically unaffected patients ${ }^{(49)}$. Based on this data, the occurrence of a hyperintens signal in the mastoid of the EGPA study population seems to be high. This could possibly be a sign of an autoimmune inflamed process, especially because there is no significant correlation between the rhinological results and the results of the MRIs (hypothesis II). According to the definition of rhinosinusitis in the European Position Paper on Rhinosinusitis and Nasal Polyps (EPOS) 2012 for epidemiological studies ${ }^{(40)}$, a high percentage of EGPA patients of this study are suffering chronic rhinosinusitis with well-known individual and health economic consequences.

The supporting history (cephalgia, nasal crusts, dysosmia and epistaxis, nasal obstruction and nasal discharge) was confirmed by rhinoscopic data (polyps, nasal discharge, turbinate hyperplasia, nasal crusts, synechia and further symptoms) and almost half of the patients (43\%) underwent one or more surgical procedures on the nose and/or nasal sinus.

In a small case series 59\% of EGPA patients were suffering from polyposis nasi at the time of diagnosis, $24 \%$ of them had sinunasal surgery with early recurrence of symptoms ${ }^{(16)}$.

In comparison to this data chronic rhinosinusitis affects about

$5-15 \%$ of the general population. The prevalence of nasal polyps is less than $5 \%{ }^{(40)}$.

History and rhinomanometric data showed a severe nasal obstruction in about one third of all patients and in $40 \%$ of the examined patients a dysosmia (general population: up to 20\%) was detected ${ }^{(50-52)}$. Dysosmia as a result of rhinosinusitis with polyps is described as sinunasal dysosmia and caused by a combination of conductive and inflammable reasons ${ }^{(53)}$.

Mediators also detected in EGPA (e.g. IL5) seem to directly influence the olfactory mucosa or possibly the neural system, while detailed knowledge of the pathomechanism is missing ${ }^{(53-55)}$. The frequent occurrence of structural nasal obstruction seems to support the hypothesis of a conductive olfactory disorder in EGPA. However, it is known that even in the healthy population, only a small portion of inhaled air reaches the olfactory epithelium (approximately 15\%). Damm et al. could only show a positive correlation between the results of the rhinomanometry and the olfactory abilities for a severe nasal obstruction ${ }^{(56,57)}$. Interestingly, there are noticeably fewer patients (13\%) with a positive history of dysosmia compared to the results of the olfactory test. However, it is known that especially patients who are suffering from chronic rhinosinusitis do not complain about a dysosmia although it is detected in olfactory tests ${ }^{(58)}$.

Compared to previously reported data, the number of patients with nasal crusting and epistaxis in this study appear to be lower (epistaxis: $16 \%$ vs. $60 \%$; nasal crusting: $19 \%$ vs. $75 \%$ ). Patient selection might influence these differing results (consecutive patients of a tertiary referral center versus a highly motivated and skilled patient support group). In addition, nasal crusting and epistaxis was confirmed by endoscopy in less than $10 \%$ of patients. The difference from the previous study might be explained by the fact that in the presented study only data from examination days is considered whereas the earlier stated study presents patient history based on patient surveys (point versus cumulative longitudinal examination) ${ }^{(23)}$. The average of the Lund-Mackay-score of all MRI scans yields 9. However, the total score would most likely be higher if the omitted analysis of the ostiomeatal complex is also considered.

Even for patients without any clinical sign of rhinosinusitis, it is known that the Lund-Mackay-score is not zero ${ }^{(59)}$. Accordingly, an average Lund-Mackay-score of 4 was found in a group of patients without clinical signs of rhinosinusitis ${ }^{(60)}$. Hence a score of 9 , as shown in this study, is valued as pathological. Furthermore a chronic inflammatory process of the sinus is likely since a thickened mucosa was detected in up to $50 \%$ of the examined patients.

The presented data of the largest monocentric study confirms the hypothesis of a high (approximately $80 \%$ ) percentage of ENT-region involvement in EGPA-patients. In addition the rhinological manifestation is possibly an important factor in the initial phase of the disease $(3,8,11-13,15,20)$.

To prevent complications and permanent damage from EGPA, this frequently occurring manifestation should be identified at an early stage. The long-term follow-ups should be managed interdisciplinary. Since the autoimmune inflammatory process itself seems to be a cause for the otological and rhinological manifestations, adjusting immunomodulating therapy should be the initial focus.

Today, EGPA is considered a chronic relapsing disease and life threatening manifestations can usually be prevented. Therefore therapeutic decisions have to increasingly include aspects of quality of life.

Hence, in addition to an accurate immunotherapy, a symptomatic therapy is of particular importance. Due to the lack of data for EGPA patients, the current symptomatic therapy should be based on the existing national and international guidelines ${ }^{(40)}$. Surgical interventions are primarily reserved for severe or acute complications ${ }^{(18)}$. Rehabilitation of functionality should be achieved to minimize the burden of EGPA.

The strength of this study is its uniform, interdisciplinary diagnostic approach. However, there are limitations based on the retrospective character and the small sample size.

\section{Acknowledgement:}

Dipl. Math. Arne Jochens for his support in statistical analysis. Sabine Lübker for her support in literature search. Martin Stager and Roop Petersen for their support to edit the text. 


\section{Author contributions}

HP: conception and design, acquisition of data, analysis and interpretation of data, drafting of the manuscript, critical revision of manuscript, final approval; PG: conception and design, acquisition of data, analysis and interpretation of data, drafting of the manuscript, critical revision of manuscript, final approval; MB: conception and design, analysis and interpretation of data, critical revisal of manuscript, final approval; $\mathrm{MH}$ : analysis and interpretation of data, critical revisal of manuscript, final approval; PA: critical revisal of manuscript, final approval; JPB: analysis and interpretation of data, critical revisal of manuscript, final approval; JH: critical revisal of manuscript, final approval; FM: data acquisition, conception and design, analysis and interpretation of data, critical revisal of manuscript, final approval; ML: conception and design, acquisition of data, analysis and interpretation of data, drafting of the manuscript, critical revisal of manuscript, final approval.

\section{Conflict of interest}

There is no conflicts of interest.

\section{References}

1. Churg J, Strauss L. Allergic granulomatosis, allergic angiitis, and periarteritis nodosa. Am J Pathol 1951; 27: 277-301.

2. Pagnoux C. Churg-Strauss syndrome: evolving concepts. Discov Med. 2010; 9: 243-252.

3. Comarmond C, Pagnoux C, Khellaf M, et al. Eosinophilic granulomatosis with polyangiitis (Churg-Strauss): clinical characteristics and long-term followup of the 383 patients enrolled in the French Vasculitis Study Group cohort. Arthritis Rheum. 2013; 65: 270-281.

4. Della RA, Baldini C, Tavoni A, et al. ChurgStrauss syndrome: clinical and serological features of 19 patients from a single Italian centre. Rheumatology (Oxford). 2002; 41: 1286-1294.

5. Guillevin L, Cohen P, Gayraud M, Lhote F, Jarrousse B, Casassus P. Churg-Strauss syndrome. Clinical study and long-term follow-up of 96 patients. Medicine (Baltimore). 1999; 78: 26-37

6. Hellmich B, Lamprecht P, Aries PM, Gross WL. Early diagnosis of vasculitides. Z Rheumatol. 2005; 64: 538-546.

7. Keogh KA, Specks U. Churg-Strauss syndrome: clinical presentation, antineutrophil cytoplasmic antibodies, and leukotriene receptor antagonists. Am J Med. 2003; 115: 284-290.

8. Lanham JG, Elkon KB, Pusey CD, Hughes GR. Systemic vasculitis with asthma and eosinophilia: a clinical approach to the ChurgStrauss syndrome. Medicine (Baltimore) 1984; 63: 65-81.

9. Pagnoux C, Wolter NE. Vasculitis of the upper airways. Swiss Med Wkly. 2012; 142 w13541.

10. Reid AJ, Harrison BD, Watts RA, Watkin SW McCann BG, Scott DG. Churg-Strauss syndrome in a district hospital. QJM. 1998; 91: 219-229.

11. Sable-Fourtassou R, Cohen P, Mahr A, et al. Antineutrophil cytoplasmic antibodies and the Churg-Strauss syndrome. Ann Intern Med. 2005; 143: 632-638.

12. Sinico RA, Di TL, Maggiore $U$, et al. Prevalence and clinical significance of antineutrophil cytoplasmic antibodies in Churg-Strauss syndrome. Arthritis Rheum. 2005; 52: 2926-2935.
13. Solans R, Bosch JA, Perez-Bocanegra C et al. Churg-Strauss syndrome: outcome and long-term follow-up of 32 patients. Rheumatology (Oxford). 2001; 40: 763-771.

14. Zwerina J, Axmann R, Jatzwauk M Sahinbegovic E, Polzer K, Schett G Pathogenesis of Churg-Strauss syndrome: recent insights. Autoimmunity. 2009; 42 376-379.

15. Bacciu A, Bacciu S, Mercante G, et al. Ear nose and throat manifestations of ChurgStrauss syndrome. Acta Otolaryngol. 2006; 126: 503-509.

16. Bacciu A, Buzio C, Giordano D, et al. Nasal polyposis in Churg-Strauss syndrome. Laryngoscope. 2008; 118: 325-329.

17. Diri E, Buscemi DM, Nugent KM. ChurgStrauss syndrome: diagnostic difficulties and pathogenesis. Am J Med Sci. 2003; 325 101-105.

18. Ishiyama A, Canalis RF. Otological manifestations of Churg-Strauss syndrome. Laryngoscope. 2001; 111: 1619-1624.

19. Martinez Del PM, Moffat D, Sudhoff $H$ Unusual presentation of temporal bone involvement in Churg-Strauss syndrome. Laryngol Otol. 2008; 122: 425-427.

20. Olsen KD, Neel HB, III, DeRemee RA, Weiland LH. Nasal manifestations of allergic granulomatosis and angiitis (Churg-Strauss syndrome). Otolaryngol Head Neck Surg. 1980; 88: 85-89.

21. Ovadia S, Dror I, Zubkov T, Tanay A, Levy D Zandman-Goddard G. Churg-Strauss syndrome: a rare presentation with otological and pericardial manifestations: case report and review of the literature. Clin Rheumatol. 2009; 28 Suppl 1: S35-S38.

22. Saka N, Seo T, Shimano K, Kashiba K, Mori T, Sakagami M. A case of Churg-Strauss syndrome with refractory otitis media. Auris Nasus Larynx. 2009; 36: 79-81.

23. Srouji I, Lund V, Andrews P, Edwards C Rhinologic symptoms and quality-of-life in patients with Churg-Strauss syndrome vasculitis. Am J Rhinol. 2008; 22: 406-409.

24. Moosig F, Bremer JP, Hellmich B, et al. A vas culitis centre based management strategy leads to improved outcome in eosinophilic granulomatosis and polyangiitis (ChurgStrauss, EGPA): monocentric experiences in 150 patients. Ann Rheum Dis. 2013; 72:
1011-1017.

25. Masi AT, Hunder GG, Lie JT, et al. The American College of Rheumatology 1990 criteria for the classification of ChurgStrauss syndrome (allergic granulomatosis and angiitis). Arthritis Rheum. 1990; 33: 1094-1100.

26. Garske U, Haack A, Beltran O, et al. Intraand inter-rater reliability of endonasal activity estimation in granulomatosis with polyangiitis (Wegener s). Clin Exp Rheumatol. 2012; 30(1 Suppl 70): S22-S28.

27. Mathers C, Smith A, Concha M. Global burden of hearing loss in the year 2000. Global burden of Disease. 2000; 18: 1-30.

28. WHO. Prevention of blindness and deafness - Grades of hearing impairment; http:// www.who.int/pbd/deafness/hearing impairment_grades/en/index.html. 2014. Ref Type: Online Source

29. DIN EN ISO, 7029:2000. Akustik - Statistische Verteilung von Hörschwellen als eine Funktion des Alters. 2000. Ref Type: Online Source

30. Hummel T, Kobal G, Gudziol H, Mackay-Sim A. Normative data for the "Sniffin' Sticks" including tests of odor identification, odor discrimination, and olfactory thresholds: an upgrade based on a group of more than 3,000 subjects. Eur Arch Otorhinolaryngol. 2007; 264: 237-243.

31. Mlynski G, Beule A. Diagnostic methods of nasal respiratory function. HNO. 2008; 56: 81-99.

32. Lin HW, Bhattacharyya N. Diagnostic and staging accuracy of magnetic resonance imaging for the assessment of sinonasal disease. Am J Rhinol Allergy. 2009; 23: 36-39.

33. Lund VJ, Mackay IS. Staging in rhinosinusitus. Rhinology 1993; 31: 183-184.

34. Lund VJ, Kennedy DW. Quantification for staging sinusitis. The Staging and Therapy Group. Ann Otol Rhinol Laryngol Suppl 1995; 167: 17-21.

35. McNeill E, O'Hara J, Carrie S. The significance of MRI findings for non-rhinological disease. Clin Otolaryngol 2006; 31: 292-296.

36. Metson R, Gliklich RE, Stankiewicz JA, et al. Comparison of sinus computed tomography staging systems. Otolaryngol Head Neck Surg. 1997; 117: 372-379.

37. Oluwole M, Russell N, Tan L, Gardiner Q, 
White P. A comparison of computerized tomographic staging systems in chronic sinusitis. Clin Otolaryngol Allied Sci. 1996; 21: 91-95.

38. Lindbaek M, Johnsen UL, Kaastad E, et al. CT findings in general practice patients with suspected acute sinusitis. Acta Radiol. 1996 37: 708-713.

39. Vogl TJ, Mack MG, Balzer J. Chronic infections of the paranasal sinuses. Radiologe. 2000; 40: 500-506.

40. Fokkens WJ, Lund VJ, Mullol J, et al. European Position Paper on Rhinosinusitis and Nasal Polyps 2012. Rhinol Suppl 2012; (23): 3-298.

41. Vaglio A, Moosig F, Zwerina J. Churg-Strauss syndrome: update on pathophysiology and treatment. Curr Opin Rheumatol. 2012; 24 24-30.

42. Johansson MS, Arlinger SD. Prevalence of hearing impairment in a population in Sweden. Int J Audiol. 2003; 42: 18-28.

43. McCaffrey TV, McDonald TJ, Facer GW, DeRemee RA. Otologic manifestations of Wegener's granulomatosis. Otolaryngol Head Neck Surg. 1980; 88: 586-593.

44. Kornblut AD, Wolff SM, Fauci AS. Ear disease in patients with Wegener's granulomatosis. Laryngoscope. 1982; 92: 713-717.

45. Acheson JF, Cockerell OC, Bentley CR, Sanders MD. Churg-Strauss vasculitis presenting with severe visual loss due to bilateral sequential optic neuropathy. $\mathrm{Br} J$ Ophthalmol. 1993; 77: 118-119.

46. Mencacci NE, Bersano A, Cinnante CM, et al. Intracerebral haemorrhage, a possible presentation in Churg-Strauss syndrome: case report and review of the literature. J Neurol Sci. 2011; 301: 107-111.

47. Sehgal M, Swanson JW, DeRemee RA, Colby
TV. Neurologic manifestations of ChurgStrauss syndrome. Mayo Clin Proc. 1995; 70: 337-341.

48. Shintani S, Tsuruoka S, Yamada M. ChurgStrauss syndrome associated with third nerve palsy and mononeuritis multiplex of the legs. Clin Neurol Neurosurg. 1995; 97 172-174.

49. von Kalle T, Fabig-Moritz $\mathrm{C}$, Heumann $\mathrm{H}$ Winkler P. Incidental findings in paranasal sinuses and mastoid cells: a cross-sectional magnetic resonance imaging (MRI) study in a pediatric radiology department. Rofo. 2012; 184: 629-634.

50. Murphy C, Schubert CR, Cruickshanks KJ, Klein BE, Klein R, Nondahl DM. Prevalence of olfactory impairment in older adults. JAMA. 2002; 288: 2307-2312.

51. Landis BN, Konnerth CG, Hummel T. A study on the frequency of olfactory dysfunction. Laryngoscope. 2004; 114: 1764-1769.

52. Bramerson A, Johansson L, Ek L, Nordin S, Bende M. Prevalence of olfactory dysfunction: the Skovde population-based study. Laryngoscope. 2004; 114: 733-737.

53. Damm M, Temmel A, Welge-Lussen A, et al. Olfactory dysfunctions. Epidemiology and therapy in Germany, Austria and Switzerland. HNO. 2004; 52: 112-120.

54. Damm M, Binkowski K, Vent J, et al. Zytokine und Entzündungsmediatoren im Nasensekret bei Riechstörung. 2007.

55. Vincent AJ, Choi-Lundberg DL, Harris JA, West AK, Chuah MI. Bacteria and PAMPs activate nuclear factor kappaB and Gro production in a subset of olfactory ensheathing cells and astrocytes but not in Schwann cells. Glia. 2007; 55: 905-916.

56. Damm M, Eckel HE, Streppel M, Jungehulsing M, Stennert E. Dependence of uni- and bilateral olfactory capacity on nasal airflow in patients with chronic rhinosinusitis. HNO. 2000; 48: 436-443.

57. Zhao K, Pribitkin EA, Cowart BJ, Rosen D, Scherer PW, Dalton P. Numerical modeling of nasal obstruction and endoscopic surgical intervention: outcome to airflow and olfaction. Am J Rhinol. 2006; 20: 308-316.

58. Delank KW, Stoll W. Olfactory function after functional endoscopic sinus surgery for chronic sinusitis. Rhinology. 1998; 36: 15-19.

59. Chen CJ, Chen DL, Chen JJ. The LundMackay Score for Adult Head and Neck Computed Tomography. J Radiol Sci. 2011; 36 No.4.

60. Ashraf N, Bhattacharyya N. Determination of the "incidental" Lund score for the staging of chronic rhinosinusitis. Otolaryngol Head Neck Surg. 2001; 125: 483-486.

Martin Laudien, MD

Department of Otorhinolaryngology

Head and Neck Surgery

University of Kiel

Arnold-Heller-Straße 3

Haus 27

24103 Kiel

Germany

Tel: +49-431-597 2324/2241

Fax: +49-431-597 2272

E-mail: laudien@hno.uni-kiel.de 